\title{
The Old Institutionalism Meets The New Institutionalism*
}

\author{
Seth Abrutyn \\ Jonathan H. Turner \\ University of California-Riverside
}

\section{Published in Sociological Perspectives (2011)}

\section{Citation:}

Abrutyn, Seth, and Jonathan H. Turner. 2011. "The Old Institutionalism Meets the New Institutionalism." Sociological Perspectives 54(3):283-306.

\begin{abstract}
As key socio-cultural building blocks of human societies, institutions are distinct from organizations and, hence, are central to sociological inquiry. In recent decades, however, institutional analysis has increasingly moved towards the analysis of organizations, while treating "institutions" as the environments or fields of organizations. While the insights offered by contemporary organizational theorists have provided important keys to understanding how organizations, especially economic organizations, adapt to pressures within their environments, we argue that the Old Institutionalism has much to offer the New Institutionalisms. In the paper below, the Old Institutional is revisited to construct a precise definition of institutions as well as posit a robust theory of institutional dynamics; a theory which supplements contemporary organizational analysis. Four dynamics stand out: the process of institutional autonomy; the intersection of stratification systems and institutions; modes of integration within and between institutions; and generalized symbolic media of exchange. In particular, the latter two occupy our attention primarily as they have been under-theorized elsewhere.
\end{abstract}




\section{INTRODUCTION}

One of the most important conceptual shifts in the analysis of organizations came in the 1970s when the environments of organizations were increasingly viewed as critical in understanding organizational dynamics. Along with a new emphasis on networks and markets, organization theorizing took a new direction. The environments of organizations were variously conceptualized along a number dimensions, such as: resource niches (Hannan and Freeman 1977), networks-market relations with other organizations (Ouchi 1980; Fligstein 1996; Powell 1999), cultural norms and ideologies (Selznick 1948; Meyer and Rowan 1977), forms of regulation by polity and law (Hirsch 1975; Edelman and Suchman 1997), and in economics especially, the "rules of the game" (North 2005). For some, this shift represented an emphasis on the ecology of organizations, viewing organizations in a Darwinian-like struggle to survive in resource niches with high organizational density (Hannan 1988); for others, the environment was conceptualized as a field of other organizations, regulatory agencies and norms, and cultural ideologies to which organizations had to adapt (DiMaggio and Powell 1983). The first line of inquiry became organizational ecology, whereas the latter was proclaimed to the New Institutionalism. Both approaches emphasized the processes by which organizations adapt to their environments and both significantly increased the accumulated knowledge of organizational dynamics.

Yet, all of this new conceptual activity has not provided a clear definition of institutions. In actual fact, the environments of organizations consisted of other organizations and their cultures, and while this basic point is certainly sound, at least in complex differentiated societies, it does not address the dynamics of institutions as 
emergent, macro-level socio-cultural formations that constrain the operation of

organizations, and vice versa. Rather, selected elements of environments-the state, law, cultural ideologies and mythologies, professional norms, resources, and the like—are highlighted as key properties of environments to which organizations must adapt. And so, the structural and cultural properties and dynamics of institutional domains themselves are not extensively conceptualized, nor examined empirically.

While the new institutionalisms continue to generate useful insights that build upon those already accumulated, we believe that older conceptualizations of institutional domains, like those provided by early functionalisms such as Herbert Spencer and Emile Durkheim, or by more modern-day functionalisms like Talcott Parsons and Niklas Luhmann and by more recent evolutionary approaches like those developed by Gerhard Lenski, Jonathan Turner, and others need to be re-introduced. The Old Institutionalisms, we argue, still have much to offer the New Institutionalism.

\section{WHY DID THE NOTION OF INSTITUTION BECOME SO VAGUE?}

For much of sociology's history, institutions were seen as macro-level sociocultural formations that organize corporate units—groups, organizations, and communities—into systems that address fundamental problems of adaptation or, in functional terms, that meet societal-level needs and requisites. Economy, polity, kinship, religion, law, education, medicine, sport, and the like would be seen as institutional domains composed of organizations located in communities and built from relations (often of authority) among status locations in groups. The interest of functionalists in institutions centered on the evolutionary process of differentiation among diverse domains, each having consequences for the adaptation of a population to its external 
environments (biophysical and socio-cultural) as well as its internal environments generated by problems of complexity inherent in the process of differentiation. Institutions were, therefore, not just fields, grids, or resource niches: they were one of the key socio-cultural formations of societal evolution and, hence, the building blocks of human societies; these domains were real, not a fiction or reification of organizations. True, their structural and cultural properties are built from organizations, but once organizations become integrated around particular problems of adaptation they reveal emergent properties that can be conceptualized independently of their constituent organizations. This emergent property can be labeled an institutional domain. Additionally, societal systems as well as inter-societal systems are built from the respective relations among institutional domains; the environment of any organization consists of relations among organizations within a domain of activity and relations with organizations embedded in other institutional domains.

There is no real conflict here between the New and Old Institutionalism, but there is a dramatic shift in focus. The New Institutionalisms emphasize other organizations, especially those with power (polity), material resources (economy), credentialing power (education), and the cultural ideologies, norms, and even myths that are generated by organizations within diverse domains. In contrast, the Old Institutionalism has been interested in the emergent dynamics of institutional domains that generate distinctive cultures and that also employ structural mechanisms integrating relations among organizations within a domain and between organizations of different domains. The Old Institutionalisms sustained its emphasis on institutions, per se, while the New Institutionalism became, in reality, the "New Organizationalism” because emphasis did 
not leave the meso-level of analysis.

The question remains: Why the shift from the Old Institutionalism to the New Organizationalism? Part of the problem resided in the fact that the definition of institutions has never been crystal clear in sociology and, for that matter, the public in general. The label institution often refers, in the colloquial mind and in the mind of many sociologists, to an organization; in essence organization and institution are often seen as the same thing by different labels. Another part of the problem is the view by many sociologists that institutions are any enduring pattern of organization and culture; and these patterns can be many things ranging from language, rules and norms, ideologies, mythologies, etiquette, eating habits, and virtually any element of culture, structure, or behaviors that is regular and persistent (e.g., Jepperson 1991:144-146). Coupled with the notion of institutionalization or the processes by which patterns of culture, structure, and behavior are built up and regularized, it should not be surprising that there is considerable ambiguity over what an institution is. Still, the significant movement away from more functional and evolutionary approach to a more process, meso-level analysis of institutions needs to be explained, and perhaps the general decline of functionalism and the corresponding rise of not only conflict theory but also cultural sociology, phenomenology, and interactionism has biased thinking toward the view that any pattern of culture and structure can be conceptualized as the environment of an organization.

\section{REINVIGORATING THE NOTION OF INSTITUTION}

Bringing a more robust and precise conception of institution to organizational analysis can add much to the "New Organizationalism.” We can begin this process of making the Old Institutionalism relevant to organizational analysis by first presenting a 
simplified but fundamental conceptual scheme about levels of social reality, as is done in Figures 1 and 2. Figure 1 emphasizes that the social world reveals a structural pattern of embedding, with encounters embedded in groups, with groups nested in organizations, organizations within communities or systems of communities, and organizations and communities within institutional domains. On the one hand, encounters are the building blocks of groups, which are the building blocks of organizations, which are the materials from which communities and institutional domains are constructed, while on the other hand, the structure and culture of institutional domains become constraints on community formations, organizations, groups, and encounters. For our purposes here, the structural embedding of organizations in institutional domains signals that the environment of all organizations (and their constituent groups and encounters) is one or more institutional domains. True, organizations interact with people, groups, and other organizations as well as their cultures, but the relationships are highly constrained by the nature of the institutional domains in which they are embedded. Figure 2 directs attention to the levels of cultural reality that, we feel, are relevant to understanding organizations and their cultural environments.

(Figure 1 about here)

Drawing from these two figures, four key structural and cultural aspects of institutions, as highlighted by the Old Institutionalism, can supplement the dynamics found in New Institutionalism as well as lead us to a clearer definition of institutions. From Figure 1, three structural dynamics inherent in embedding and in the interrelationships between institutions and other macro structural elements are particularly important. First, institutional autonomy draws attention to the organizational 
dynamics in which one institutional domain become increasingly discrete vis-à-vis other domains (Abrutyn 2009). Second, the relationship between institutions and the extant societal stratification system is key to understanding the way organizations, institutional and organizational resources, and individual actors are distributed in space. Third, and part of the crux of this paper, are the ways in which increasingly autonomous institutions develop distinct modes of integration which have important consequences for organizational formation, adaptation, and dynamics across institutional domains.

Figure 2 emphasizes important cultural dynamics, where a fourth institutional dynamic can be found: generalized symbolic media of exchange. Drawn from an insight first noted in Simmel's (1907) analysis of money, but which became a feature of Parsons and Smelser's (1956) economic theory: exchanges within institutional domains are facilitated and constrained by generalized (symbolic) media of exchange. Cultural systems—ideologies, meta-ideologies, and norms—shaping the institutional environments of organizations are built up around the generalized symbolic media that evolve within institutional domains. Below, we will look at all of the key properties of institutional domains, but the focus will be on the dynamics around (1) cultural formation within institutional domains and (2) structural integration within and between domains.

(Figure 2 about here)

\section{Cultural Properties of Institutional Domains}

A key insight found in the Old Institutionalism was that institutional domains, as they grew increasingly autonomous and differentiated from each other, developed their own distinctive generalized symbolic media of exchange. Parsons and Smelser (1956) argued that exchanges within the economy are coordinated by the symbolic medium of 
money, while exchanges in the polity revolve around the medium of power. In each of the four quadrants of Parsons’ AGIL scheme, where institutions evolved, distinctive media regulate exchanges within this quadrant, and between corporate units in different quadrants. The result of Parsons and Smelsers's analysis was a series of two-way exchanges using symbolic media within and between institutional domains. Niklas Luhmann (1984) would later shed the AGIL and extend this analysis of symbolic media to institutions while also elaborating the effects of media on interaction between corporate units and individuals. For Luhmann, media of exchange were like symbolic 'bundles' that both (1) facilitate and (2) constrain action and interaction by delimiting the themes of discourse (thematization), the exchange of other resources, and ultimately, the circulation and diffusion of ideologies or evaluative beliefs. These facilitating and constraining effects of symbolic media are each examined below.

Facilitating Social Exchange. Essentially, generalized symbolic media are just that: symbols that can be used by actors within domains and often between domains. They are the symbols that organize talk and cognitions within a domain; they are what individual and corporate actors often exchange; they are often the valued resources unequally distributed to individuals by corporate units leading to patterns of inequality and stratification of a population; they are used to formulate world views and themes that often differentiate individual and corporate actors across institutional domains (i.e., universities versus law firms, or professors and lawyers); and they are the symbolic ingredients of ideologies that evolve within a domain. Let us illustrate. In more advanced economies, money is the generalized symbolic media of exchange and it is used in all the ways just enumerated. Economic actors talk about money and are oriented toward 
accumulating money (especially in capitalist economies); it is the valued resource exchanged within the economy; it is exchanged for the generalized symbolic media of other domains (say, money to support polity in exchange for allocation of autonomous authority and rights to influence from, respectively, polity and law to coordinate actions of individual and corporate actors); it is the valued resource unequally distributed and, hence, one pillar of a stratification system; it is part of the world view among actors in economies; it is the basis for the ideologies of the economy that inform both individual and collective actors of what is right and wrong, good and bad, appropriate and inappropriate action within the economy; and it is the symbolic medium that constrains the evolution of both institutional and organizational norms within a domain and its constituent corporate units

Let us take another example of a less tangible symbolic medium: love/loyalty in the family. Discourse and talk within the family are about love and loyalty, or perhaps the lack thereof; it is the valued resource exchanged within the kinship domain and it is exchanged for other media from other domains (e.g., money to family members for their loyalty to work; allocation of authority by polity to adults in kinship for loyalty from these adults toward polity); it is part of the cognitive set, world views, and themes of those operating within kinship; it is the highly valued resource that, like all symbolic media, is unequally distributed and hence part of the stratification system (a fact too often ignored by sociologists with their concern, if not over-concern, with money, power, and prestige); it is the evaluative basis for ideologies informing individual and collective actors of what is good and bad, right and wrong within the family; and these ideologies constrain the institutional and organizational norms that evolve within kinship. Thus, 
what is true of money and love/loyalty is also true of power, sacredness/piety, influence, health, learning, knowledge, and other media in other institutional domains. In Table 1, we provide a tentative list of other media and the institutions in which they evolved.

(Table 1 about here)

In essence, to the extent that culture is an important dimension of the environment of organizations, culture is built from the use and then codification of the evaluative and regulative aspects of generalized symbolic media into discourse, cognitive-sets and world-views, and ideologies. Culture has to come from somewhere, and while it is certainly true that individuals generate culture as they act, interact, and organize, they do so through the use of generalized symbolic media. Equally significant, depending upon the relative dominance of one or more institutional domains, the cultural environment of organizations will be disproportionately influenced by the ideologies of these dominant domains. For example, if sacredness/piety from religion dominates, the cultural environment of kinship, law, polity, and education will be heavily influenced by the ideology and norms built from this medium; similarly, if money from economy or power from polity dominate, then the ideologies built from money and power will be disproportionate part of the cultural environment of any organization, even those outside of the economy and polity proper. And, in cases where multiple domains become dominant, the media become (unevenly) integrated into meta-ideologies.

Circulating Media. The above suggests another property of generalized symbolic media: their circulation across institutional domains and organizational units in these domains. When symbolic media are exchanged by actors in different domains, they begin to circulate across institutional boundaries. Some media circulate more readily than 
others—above and beyond specific exchanges among actors. Several conditions affect how rapidly and across how many domains a generalized symbolic medium is likely to circulate. One is the relative "coolness" or "hotness" of the medium itself, or the propensity of media to generate emotionally charged ideologies that impose restrictions on the behaviors of both individual and corporate actors. Money, knowledge, learning, and power are relatively cool media compared, for example, to love/loyalty and sacredness/piety. "Cool" media circulate more readily in more domains primarily because they do not generate intense moral codes in their respective ideologies that limit permissible actions.

Another key condition affecting the circulating of a generalized symbolic medium is its capacity to build complexity or place limits on complexity. As Simmel and Luhmann both emphasized, money builds complexity as it circulates by dramatically simplifying actors' exchanges and increasing the capacity to express preferences in markets (and indeed, to extend markets to virtually all domains). Moreover, the "coolness" of money means it can be used within virtually all other institutional domains-e.g., conversion of entrance requirements into monetary payment of fees dramatically increases how complex education, polity, religion, law, and economy can become. Similarly, power as franchised authority given by polity to organizations in all other domains can increase complexity by attaching systems of authority to division of labor and allowing organizational grow in size and complexity, as well as in their diversity (Weber 1978). In contrast, a medium like love/loyalty or sacredness/piety inhibits complexity as it restricts actions and the complexity of structures and relationships among organizational units. 
A third condition related to their circulation and relative dominance across domains has been termed "colonization of the lifeworld" by Habermas (1985). We do not need to go so far as Habermas, but there is a propensity not only for some media to circulate more than other media but also for these "cool" media to displace, to varying degrees, the indigenous media and the ideology and norms formed from this media. Media that give emotional meaning and anchorage—-media such as love/loyalty and sacredness/piety—do not necessarily disappear when money, power (as authority), or learning enter a domain, because their emotional moorings provide a strong capacity to resist "corruption" and "pollution." However, they are influenced by the presence of "cooler" media in transactions and in the ideologies that these media bring with them; the culture of any unit in a domain like kinship, religion, or education will contain ideological elements from economy, polity, and law with the result that this culture will be very different than in societies where money and power have not penetrated transactions and actions within domains.

Media and Meta-ideology. Because symbolic media circulate at different rates and distances across institutional domains, the cultural environment of any organization will be disproportionately influenced by those media able to circulate rapidly and widely. In a modern capitalist society, it should not be surprising that the cultural environment of any organization is disproportionately a meta-ideology or combination of the ideologies built up from money, power and influence, coupled with elements from learning, knowledge and competitiveness. For example, Meyer's (1977), emphasis on the "rational mythology" of western modes of education as a condition for making loans to developing countries is not so much a mythology but rather an application of the meta-ideology of 
advanced capitalism in order to legitimate control of dependent societies in the worldsystem (see also Bourdieu 1984; Meyer, Ramirez, and Soysal 1992; Meyer, Nagel, and Snyder Jr. 1993). It is a clear that polity, economy, education, and perhaps science are dominant institutional domains in advanced capitalist societies and so is the metaideology that combines the symbolic media from these domains into a cultural "program" imposed upon other societies, thereby enabling western capitalist societies to exercise some structural control over institutional domains (and organizations in these domains) of less developed societies.

It will become clear that the properties inhering in generalized media enumerated above influence the structural properties of institutional domains as well as the organizational dynamics outlined by the New Institutionalism. Most especially, when we consider the ways in which autonomous institutions employ different combinations of modes of integration in light of the circulation of media of exchange and imposition of meta-ideologies, a more robust institutional environment can be conceptualized, which can supplement emphasis on fields in the New Institutionalist tradition.

\section{Structural Properties of Institutional Domains}

With structural embedding, symbolic media of exchange have conduits to circulate from the macro-level institutional domain down to organizational units to groups within organizations, and across communities. The culture exerts its greatest influence by traveling across the networks among organizational units within a domain and, of course, in the networks connecting organizational units across domains. While mass media can move symbolic media and the ideologies (and normative systems) built from them across a population-indeed the entire world-system of societies - these 
ideologies and the meta-ideologies and cultures of a domain exert more influence when traveling along networks of exchange between organizations and systems of authority in divisions of labor within organizations. Ultimately, it is when culture is attached to interactions in encounters lodged in corporate units like groups and organizations that they have their greatest effects in transmitting the culture of a domain to both collective and individual actors.

Institutional Autonomy. At the macro level, a key structural property of any institutional domain is its degree of autonomy from other domains (Abrutyn 2009). Institutional autonomy is a process by which primary corporate units secure structural and symbolic independence vis-à-vis other corporate units. Independence allows these corporate units, or institutional entrepreneurs, to reconfigure their relationships with other corporate units and carve out autonomous space for their activities. Domains never become fully autonomous because of the circulation of media of exchange and the divisions of labor between institutional domains. For example, law is almost always attached to polity since the enactment of law and its enforcement are conducted by agents of the state in most societies of the modern world, while modern democratic nations depend on a relatively autonomous legal system to secure and sustain legitimate authority (Weber 1967). In capitalist societies, economy is more autonomous from polity than in socialist societies by whatever name; in preliterate societies such as those organizing horticultural activities, economy and polity are heavily embedded in kinship and, therefore, not nearly as autonomous as they are in modern capitalist societies (Earle 2002).

As a domain becomes more autonomous, exchanges and interactions are 
increasingly facilitated as well as constrained by its particular medium of exchange. The more this medium structures behaviors of actors in communities, organizations, groups, and encounters in a domain, the less likely are media from external domains to become part of the environments of corporate units in a domain. For example, in the U.S., because religion is relatively autonomous from polity—within some general legal guidelines, the structure and culture of polity exerts a lesser force on church organizational units. If anything, it is the other way around: the political arena as a part of a democratic polity must take into account the cultural and demographic profile of religious organizational units. In theocracies, however, the polity tends to be more autonomous than the religious domain (Eisenstadt 1963), while religious organizational units are much more dependent upon, and influenced by, political media of exchange (Lenski 1966).

Stratification and Categoric Units. Inequalities in the distribution of valued resources—often the generalized symbolic medium of a domain—occur within corporate units of a domain. Individuals at different locations within the divisions of labor of corporate units will typically receive varying levels of resources, thereby generating inequalities in the macro-level distribution of resources of a population. On the basis of their configuration of resource shares individuals tend to converge in their cognitive outlooks, world-views, beliefs, behaviors, and propensities to experience positive and negative emotions, living arrangements, life-styles, spending patterns, and other features that distinguish "classes" of persons. If there is a relatively clear convergence among these features, a distinct set of social class will emerge, even if their respective boundaries are often fuzzy and vague. The boundaries of classes become less clear, 
however, when a fuller range of resources is examined, as can be seen by viewing all generalized symbolic media as valued resources or, in more limited ways, other forms of "capital" such as social, cultural, and symbolic capital being distributed like other stratifying resources like economic capital or power. A class can be seen as a categoric unit because it represents a categorization of persons as distinctive by virtue of their share of resources and inevitably leads to their differential treatment in social interactions and in access to resource-distributing corporate units within institutional domains.

Addtionally, unequal access to these media becomes the principle criterion for evaluating the relative worth of individuals in diverse categoric units and for legitimating the unequal distribution of other valued resources (Berger, Cohen, and Zelditch Jr. 1972; Ridgeway 2006). These ideologies are typically combined into the meta-ideologies. For instance, if kinship and religion are the dominant institutional domains in a society, then the ideologies of these domains will exert more influence on the evaluations of individuals - i.e., the class system will be defined by the respective shares of love/loyalty and sacredness/piety that individuals possess. If, however, economy and polity are dominant domains, then the meta-ideology legitimating stratification will be disproportionately composed of the symbolic media and ideologies of these domains: people will be evaluated by their money and power, and the lack of either will serve as a basis for stigmatizing such persons and for discriminating against them. These stigmatizing (or valorizing) beliefs become part of what expectation-state researchers in social psychology term status beliefs (Ridgeway 2001).

We emphasize these macro-level dimensions of stratification because they are often part, at least implicitly, of the analysis of organizational ecology and the "fields" in 
New Institutionalisms. Within organizational ecology, members of categoric units can become resources for organizations seeking human or other resources from incumbents in categoric units (McPherson and Ranger-Moore 1991); the field of any organization also includes distinctive categories of persons, whether believers of a religious faith, age cohorts, gender, or persons of diverse ethnic backgrounds. While the New Institutionalism tends to emphasize training and professions (as outcomes of possessing such resources as learning and knowledge) acquired in corporate units of other institutional domains, categoric units are also generated by persons' degree of access to various configurations of resources. If income is correlated with ethnicity, a system of ethnic stratification is superimposed on the general class system; and members of this consolidation of parameters, to use Blau's $(1977,1994)$ terminology, will be differentially evaluated by both their ethnicity and amount of money. Ultimately, the immediate environment of any organization is not just other corporate units but also categoric units marking individuals off as distinctive. Moreover, the culture of this environment will include more than the ideologies and meta-ideologies of the domains in which corporate units operate; the meta-ideologies and the status beliefs drawn from them to label persons in categoric units are used to evaluate members of categoric units and to legitimate the broader patterns of unequal distribution of resources in the stratification system.

Modes of Integration. Another structural property of institutional domains are the modes and mechanisms of internal integration among their constituent organizational units. As domains become increasingly autonomous they develop unique configurations of these integrative mechanisms reflecting, in part, the unique cultural environment 
evolving. The particular configuration of integrative mechanism will exert large effects on how, and to what degree, the structure and culture of an institutional domain and other domains influence the operation of a specific organizational unit within a domain. In Table 2, we list what we see as the basic structural mechanisms of integration within institutional domains. As we will argue, the particular configuration or profile of mechanisms of integration evident within a domain as well as the nature of the symbolic media and culture of a domain (i.e., ideologies, norms) can be relevant to the analysis of organizations in this domain and to organizations in other domains when (a) the domain is dominant, (b) its symbolic medium circulates widely, and (c) its ideology disproportionately influences the meta-ideology composed of constituent ideologies of differentiated institutional domains. Before returning to the issue of integration among corporate units within and between domains, we need to offer a more formal definition of institutional domain and, then, complete the picture of structure and culture outlined in Figures 1 and 2.

(Table 2 about here)

\section{Definition of Institutional Domain}

The discussion thus far provides the key elements of this definition: An institutional domain is a set of corporate units that evolved in response to selection pressures or problems of adaptation facing members of a population and, as this set of corporate units evolves and grows increasingly independent of other corporate units, it develops a distinctive generalized symbolic medium used to form an intra-domain culture, a distinctive set of corporate-unit formations, and a distinctive configuration of mechanisms for integrating relations among its 
constituent corporate units and, at times, the relations of these units and their culture and symbolic media with units in other institutional domains.

In sum, then, institutions are constructed from corporate units, which are formed in the process of dealing with population-level problems of adaptation. As corporate units evolve and become integrated by the structural and cultural mechanisms listed in Table 2, these configurations of integration become the environments to which organizations (and other types of corporate units) must adapt. The viability of the domain as a whole is a joint function of the degree to which the set of corporate units in a domain can find solutions for problems of adaptation facing a population, while at the same time adapting to the environments created by modes of integration of corporate units within and between institutional domains.

As corporate units evolve and differentiate, they distribute resources unequallymost of which are the generalized symbolic media evident in each domain—and thereby create a system of stratification composed of class categoric units and, typically, of other categoric units whose members receive differential shares of resources as a result of discrimination and its legitimatization by the meta-ideologies (and status beliefs) built up from ideologies made possible by discourse and thematization from generalized symbolic media. The manner in which both corporate and categoric units are integrated, respectively, into institutional domains and stratification systems will form the environment of any given corporate unit, especially organizations as one form of corporate unit. While it is certainly true that organizations respond to their immediate environment of other organizations and categories of persons, this environment is determined by macro-level dynamics as they cause the differentiation of institutional 
domains and the formation of stratification systems. And, by knowing how these macrolevel dynamics operate, a more robust picture of the environments of organizationswhether as resource niches or as fields — is produced. Let's elaborate upon the brief summaries in Table 2.

Segmentation as a Mechanism of Integration. This mode of integration revolves around reproduction of like corporate units, whether these are groups, organizations, or communities. Segmentation's integrative effects derive from the increasing likelihood that each new corporate unit will carry a culture similar to existing units within a domain. Thus, the same generalized media will facilitate and constrain discourse and themebuilding in exchanges of actors within corporate units and between units in different domains, while also producing somewhat shared legitimating ideologies, institutional norms, and specific norms regulating behaviors of incumbents in the division of labor of organizations. The more segmented are the corporate units in a domain, the greater will be the power of symbolic media and ideologies built to regulate the action of corporate units and individuals in these units; and the more will the environment of any given corporate unit consist of actors using this generalized symbolic medium in exchanges and discourse among actors in a domain. This proposition does not deny the possibility of other generalized media circulating within the domain, but rather posits the typical strength or efficacy of other media: greater segmentation generally implies the weaker effects of other media and ideologies. In a sense, its generalized symbolic medium becomes "hot" and more particularistic because it carries heavy moral and evaluative loadings. "Hot" media prove to be powerful in producing commitment such that institutional domains dealing in "colder" media, such as the polity or economy, attempt to 
borrow or integrate media like love/loyalty to facilitate normative orientations which are less costly to monitor and sanction and which reduce uncertainty.

These generalizations are more likely to hold true if there are structural equivalences in the divisions of labor of corporate units within a domain; and, structural equivalences are, by definition, more prolific where segmentation is the primary integrative mechanism. That is, the nature of positions, their relations to each other, and the norms organizing these relations will be approximately the same. For example, corporate units constituting an autonomous legal institution will evidence similar structural forms and their incumbents similar status locations; these incumbents will be exposed to (relatively) the same culture and, moreover, to similar configurations of relations with other locations in the unit. In addition, lawyers, law professors, and judges will be structurally equivalent with similar patterns of relations with each other as well as with the positions in the corporate units of other domains, such as family corporate units (and their divisions of labor) within the kinship system, political corporate units, economic corporate units, and so on. The data generally support the generalization that persons who are structurally equivalent develop common world-views and behave in similar ways (Sailer 1978), thereby reinforcing the regulatory control that comes with the common culture among corporate units.

The combination of common culture and structural equivalences in organizational forms is a powerful mode of integration. In the early growth of human societies in their evolutionary history, segmentation was the first response to selection pressures to organize larger populations (Maryanski and Turner 1992; Turner and Maryanski 2008). To be sure, segmentation remains the dominant mode of integration in the kinship system 
where, even in post-industrial systems, similar nuclear units are continually produced and re-produced, revealing a common culture, structurally equivalent relations with their members and with member of other kin units and, to a large extent, with actors in other institutional domains. This means that incumbents in these units will be oriented to employ the same generalized symbolic medium (love/loyalty) with fellow kin members and will exchange love/loyalty (or, more often, just loyalty and commitment) with actors in other institutional domains (e.g., willingness to come to work for pay, legitimization of polity for autonomy of authority within the family unit). They will also adhere to the evaluative cultural codes in the ideology of kinship, and be regulated by similar normative constraints. In modern complex societies, segmentation remains the most likely form of growth and integration outside of the kinship domain because these integrative dynamics work for corporate units in virtually all domains. Even as differentiation occurs, sets of corporate units—e.g., car companies, universities, law firms, sports teams, and churches—are culturally and structurally equivalent, and they are likely to have similar patterns of relations with other types of organizational units within a domain and with organizational units of other domains. Indeed, entrepreneurs creating new organizational units will often look at those units that have been successful and copy their structure, as the New Institutionalism implies with its notion of mimetic isomorphism in fields (DiMaggio and Powell 1983).

Ultimately, in domains where segmentation is primary to other mechanisms, the result is for the ideology of such domains to be highly constraining on the actions of each individual within the division of labor and corporate units as a whole. Family members, worshipers, students and faculty, scientists, and athletes are likely to hold very similar 
world-views, reveal commitments to the same ideologies, and conduct discourse with the same generalized symbolic medium. Adaptation to the environment by each segmented corporate unit involves actions that reinforce their common culture and patterns of structural equivalence, even when the environment contains differentiated organizational units of other domains. And, when the environment includes organizations from other domains, the generalized symbolic medium of a domain will be exchanged for that of another domain, though the ideology of the domain will generally remain intact and resist, in Habermas’s (1985) terms, “colonization” by the media of another domain. Yet at some point, segmentation is no longer adequate, and as we shall see below, differentiation among corporate units increases and, with differentiation, other mechanisms of integration become operative within a domain

It is worth noting DiMaggio and Powell (1983), in conceptualizing institutional environments as "organizational fields," implicitly replace the concept segmentation with isomorphism, though the two are essentially the same. Both normative and regulatory isomorphism deliberately drive convergence in organizational form within a given field (Sutton et al. 1994; Dobbin and Sutton 1998), while mimetic isomorphism produces pressure for convergence in the face of uncertainty. In particular, normative isomorphism is a process by which certain elements of institutions become necessary componentsstrategically, professionally, and even morally—to any economic organization. What may begin as purposeful regulation on the part of the political sphere becomes normatively defined over time, and new organizational units face strong pressure to adopt common cultural practices in both structure and symbol (Sutton and Dobbin 1996). Other times, new or extant organizations face uncertain environments or environmental changes and 
look to other representational organizations for guidance (Biggart 1991); mimetic isomorphism is simply one more dimension of the general integrative mechanism segmentation.

Structural Differentiation as a Mechanism of Integration. The creation of new types of corporate units with distinctive goals, divisions of labor, and to some degree, cultures is often a response to problems of segmentation which, as societies grow, increasingly becomes an inadequate mechanism for integrating relations among the units within and between institutional domains. Differentiation often emerges vertically, as hierarchical positions are generated to coordinate and regulate the exchanges and interactions of segmented units. Differentiation can also be a horizontal process by which a functional division of labor is produced in an effort to reduce the level of competition over scarce positions and to increase productivity or output. Differentiation, however, creates its own integrative problem of how to manage relations among units revealing different goals, potential conflicts of interest, somewhat diverging cultures, and inequalities in their resources. As such, differentiation is the force setting into motion selection pressures for virtually all mechanisms of integration listed in Table 2. Yet, differentiation does have some integrative consequences that are worth examining.

The evolution of distinctive, autonomous institutional domains began with the initial differentiation, from kinship, corporate units devoted to economic, political, and religious activity. For much of human societal evolution, economic and political activity was embedded in bands of hunter-gatherers and the unilineal descent system of horticulturalists, while problems of adaptation were met, at least early on, through internal differentiation of kinship (e.g., lineages, clans, sub-clans, and moieties). Larger 
populations were effectively integrated through kinship differentiation, while segmentation continued to act as the mechanism promoting a relatively shared cultural pattern operating as the institutional environment coordinating, facilitating, and constraining political, economic, and religious activity. As Abrutyn and Lawrence (2010) argue, the processes of differentiation and segmentation works until certain thresholds are passed in which groups face serious problems of coordination and regulation, whether from hostile neighbors who press up against the independence of the group in question or from internal social conflict emerging out of diverging interests (cf. Johnson and Earle 2000).

Eventually, we see the appearance of actors politically distinct in their concerns, goals, normative behavior vis-à-vis kinship actors. These political actors sought to distance themselves spatially and symbolically by building palaces on top of hills, constructing cities within cities, and engaging in prestige markets to procure goods that demarcated their status position in a new institutional domain (Postgate 1977). Power gradually replaced loyalty/love as the primary medium of exchange 5,000 years ago in ancient China, Egypt, and Mesopotamia (Adams 1966; Yoffee 2005). To be sure, their autonomy was not complete then and still remains somewhat intertwined with kinship today; the palaces (and later temples) were understood to be households much like we call the President's work place and residence the White House; nepotism and hereditary succession were still key regulating patterns; and loyalty was and still is a vital medium of exchange, especially within the smaller, inner circles of polity.

It is important, however, to note corporate units that split off from a distinctive institutional domain often have conflicts with the units in the domain from which they 
have evolved. Early political actors sought ways to penetrate the kinship domain to gain wider influence, reduce the costs of pursuing their goals, and promote their vision of reality. In the nascent autonomous political domain, especially, political actors as early as Sargon of Akkad (c. 2350 BCE) recognized the corrupting influence familial loyalties had on political decisions and goals, and took purposeful steps to reduce their effects (Nissen 1988). He created, for instance, a new capital forcing his bureaucracy and army to move from their natal homes and their 'clans' and extended families. Thus, in the process of developing a distinctive medium of discourse and exchange as well as articulating new ideologies, increasingly distinctive corporate units struggle to establish boundaries of differentiation between the emerging physical and symbolic space denoting their activities and concerns from that of other bounded spaces.

We propose that the more differentiated are the units within and/or between domains, the more likely is the environment of corporate units in domains to be dominated by structural as opposed to cultural mechanisms of integration. Vertical differentiation or" hierarchicalization,” for instance, emerges in the case of a kinship unit or units (e.g., chiefs and their lieutenants) as a relatively discrete corporate body, increasingly devoted to dealing with political problems, setting political goals, and acting 'politically', grows (Earle 1991); later, an independent polity—setting goals and making collectively binding decisions for increasingly disparate kinship corporate units whose spatial density grows quicker than mechanisms of cultural integration can keep paceemerges to solve other adaptive problems (Abrutyn and Lawrence 2010).

Thus, once institutional differentiation and internal organizational differentiation within a domain occur, the pattern of structural integration of these differentiated 
organizational units determines the environment for all other organizational units. Since most organizational theory begins with an existing pattern of differentiation of institutional domains and organizational units, less attention is paid to how they have evolved and how they have become integrated over time. In our view, the evolution of structural integration within and between institutions and their constituent corporate units give us an old but, for the New Organizationalism, new way to conceptualize the environments of organizations and their dynamics. For instance, much of Meyer's (1977) work has focused on the convergence of certain westernized 'organizational templates' such as the bureaucratic form of the Catholic Church, the belief in rationality being commensurate with efficiency and productivity, the Nation-State as the only legitimate political template, and the promise and payoff of mass public education (see also Meyer 1987; Meyer, Ramirez, and Soysal 1992). The lack of clarity regarding the institutional environment leads to a Hegelian mechanism of diffusion: Western 'institutional blueprints' appear in Meyer's work to 'unfold'. Bringing in more of the Old Institutionalism and its focus on integrative mechanisms allows us to better explain (1) why these templates of organizational form emerged in the first place in the west, (2) why they have diffused across societies, and most importantly, (3) why foreign integrative mechanisms are grafted onto indigenous structural mechanisms.

Structural Interdependencies as Mechanisms of Integration. In Table 2, types of socio-structural interdependencies are listed: (a) exchange, (b) domination, (c) inclusion and embedding, (d) mobility, (e) overlap, and (f) intersection of parameters (marking categoric membership). Depending upon which of these mechanisms is dominant, their configuration within the field or environment of any organization will vary. 
Exchange. When corporate units form exchange relationships with each other, they become structurally interdependent because each provides the other valued and often necessary resources. This interdependence generally involves exchanges of the generalized symbolic medium of an institutional domain. For example, when kin units engage in bridal exchanges across selected clans, there is a material exchange- - the bride as a resource and perhaps a monetary-based dowry—but also an exchange of the generalized symbolic medium of kinship — or at least the loyalty side (and perhaps love as well). When two companies within a capitalist economy exchange, one provides a material resource or service in exchange for money, with the money being used to secure resources from other corporate units within this domain (e.g., needed services, raw materials from other economic units) and often resources from units in other domains (such as loyal workers from kinship, influence from law, authority from polity, and so on). Thus, more than just material resources are the basis for interdependencies; there is always an exchange of the symbolic medium within a domain by at least one of the partners to the exchange and usually both (Parsons and Smelser 1956). It is proposed, then, the more a domain relies upon exchange as its basis for interdependencies and the more differentiated are corporate units in this domain, the more likely is interdependence to extend across diverse institutional domains, and the more likely is exchange to involve different symbolic media.

Domination. Domination is the use of power by a corporate unit to regulate and control other social units. There are several bases of power (Mann 1986; Turner 1995, 2010): coercive, symbolic (ideological), administrative, and material incentive. All of these are consolidated by corporate units, but to different degrees and in varying 
combinations and configurations. The form of domination will vary with which combinations of these bases are employed by corporate units. Within corporate units, hierarchies of authority, use of wages or other goods/services as material incentives, corporate culture (as it draws symbolic power from institutional ideologies), and at times, physical coercion can all provide a basis of integration. At the macro-institutional level of social organization the most relevant forms of domination are those used by core corporate units within a differentiated domain and by sets of core units in one or more domains regulating the actions of corporate units (and individuals in them) in other domains. As the scale and the level of differentiation within and between institutional domains increases, this latter form of domination is most likely to evolve and, typically, be lodged in polity and law but, at times, in economy or religion. The institutional source(s) of domination, the configuration of the bases of power used by the core corporate units in this (these) domain(s), and the degree of power consolidated and mobilized all affect the environments of corporate units in any domain. Moreover, the degree of differentiation and autonomy of domains, as well as the mechanisms of integration within and between these domains, constrains and, at the same time, often reflects the modes of domination by corporate actors in particular domains.

Embedding/Inclusion. When smaller corporate units are embedded in larger, more inclusive units, the degree of structural interdependence among corporate units increases. Inclusion and embedding typically occur within an institutional domain, as is the case with economic units when they merge, with systems of educational corporate units in lower education or universities lodged inside a more inclusive state-wide system, with churches within religious dominations, sports teams within leagues, with health 
providers in health-care networks, and local and state political parties inside of national parties. Structural inclusion is a strategy to reduce environmental uncertainty by establishing systems of authority and contracts within one larger corporate unit. In capitalist economies, for instance, mergers are a means for reducing competition and regularizing exchanges with key clients or suppliers; in many nation-states, embedding of virtually all education within a central ministry of education increases the authority of the state over education but equally important establishes standardized curricula and stable relationships among educational corporate units

With inclusion comes not only structural control but also cultural control by (1) regularizing the generalized symbolic media in play and the exchanges using these media, (2) codifying these media into ideologies that become part of the common corporate unit culture, and (3) establishing norms across congeries of corporate units that organize the divisions of labor within each embedded corporate unit while regularizing relations among corporate units inside the more inclusive structure and with corporate units outside this structure. The combination of cultural unification and administrative controls across corporate units significantly reduces uncertainty but it can also create structural and cultural rigidities within wide sectors of institutional domains or even interinstitutional relations, thereby decreasing the adaptive capacity of the more inclusive unit and, if these units are sufficiently large, the society as a whole.

Mobility. Movement of individuals across corporate units within and between institutional domains increases rates of interaction among individuals from diverse corporate-unit cultures and, often, from diverse categoric units as well. High rates of interaction among individuals, per se, tend to increase solidarity and reduce the effects of 
cultural differences and salience of categoric unit distinctions (Blau, Blum, and Schwartz 1982). Mobility is often taken for granted because it is a common linkage between institutional environs in modern, highly differentiated societies. Yet, mobility has not always been present. When mobility between types of corporate units is standardized, this pattern of mobility reduces environmental uncertainty. For example, when educational credentials, especially those in clearly-defined professions (law, engineering, teaching), are used as the graduated parameter (to use Blau's term) for regularizing mobility, environmental uncertainty is reduced for both the educational corporate units and those corporate units that employ graduates from these units. The educational unit has a more stable "market" for its graduates, while the employing unit is guaranteed a certain level of competence. Moreover, mobility regularizes exchanges of generalized symbolic media across institutional domains—say, learning and/or knowledge for money—while integrating the ideologies of the two domains into a partial meta-ideology. Additionally, there is often a process of anticipatory socialization of students in educational corporate units into the culture of the corporate units in which they will eventually be employedas is clearly the case with business, law, and engineering schools in higher education corporate units. The same would be true of vocational programs in various kinds of educational corporate units.

The end result is a dramatic reduction in uncertainty in the environments of all corporate units that have established regularized patterns of mobility within and between corporate units, even in market-driven societies where market instabilities penetrate all institutional domains. There is predictability in the qualifications of those moving between structural locations in different corporate units and especially so when this 
movement is across institutional domains; and with this movement, the culture of diverse institutional domains is integrated. For example, at noted above for movement between educational corporate units and other types of corporate units requiring learning, the exchange of generalized symbolic media is regularized, the ideologies of diverse domains are reconciled, and other elements of culture are sent to the educational domain and imparted to students who will then bring the culture of the educational domain to units in diverse domains employing it graduates. These same dynamics occur in other kinds of regularized mobility, as is the case when workers from families move in and out of corporate units in economy and other employing units in diverse domains, when government employees move in regularized patterns from their positions in government to structural locations in the economic, educational, legal, and/or other differentiated domains.

Boundary Overlaps. Because institutional domains are never fully autonomous systems, there are always physical locations in which overlapping institutional environments create unique dynamics between corporate units. A university campus, for example, brings together various corporate entities acting as liaisons between their institutional domain and the educational domain. Research institutes receive monies from outside sources; some administrators interact with agents of political, economic, kinship, and in many cases, religious domains; and various economic and political agents have offices on campus in efforts to engage and connect with students and faculty. In many cities, one will find the seat of local government resting beside the federal governments offices, as well as the chamber of commerce, the primary courthouse, and a whole host of support actors such as bail bondsmen, law offices, restaurants, churches, and other 
businesses. The effects of these overlaps are much the same as we saw in that of inclusion and mobility: where the overlaps occur, environmental uncertainty is further reduced and the exchange of generalized symbolic media is regularized, as is the movement of personnel across corporate units. Moreover, the various symbolic elements such as ideologies and norms can be much more easily integrated in these overlaps than in places where corporate units are further removed from extra-institutional actors. In essence, the salience of the boundaries are compromised by the physical and cognitive presence of various corporate units. Small towns, for example, are characterized by blurry among between polity, law, religion, and economy because nearly all of the key corporate units are physically near each other, and in fact, may share personnel (thus reducing categoric membership while promoting a shared culture across institutional domains). To be sure, the opposite is possible under the right conditions: a legal department embedded within an economic organization, meant to handle its legal transactions, often highlights the differences between legal and corporate culture more so than blurs the lines. That is, the problems the legal actors deal with are typically far removed from the insular culture of the economic organization, both physically and cognitively.

Intersections. In Blau’s $(1977,1994)$ conceptualization, parameters placing persons in socially-constructed categories, or categoric units (Hawley 1986), are of two kinds: nominal that denote individuals as either in or out of a discrete category and graduated that denote membership in categoric units by relative access to a resource(s). As noted above, corporate units in institutional domains distribute valued institutional resources unequally. Eventually this unequal distribution creates the classes of the 
stratification system, which are often categorized as rich, poor, or middle class (as well as other class distinctions based upon graduated parameters defining relative amounts of other resources such as power, influence, and other symbolic media). As classes form, status beliefs (derived from institutional ideologies and meta-ideologies) come to define individuals distinguishable by one or more nominal parameters-e.g., ethnicity, age, race, gender-as more or less worthy, which can lead to discrimination forcing them to lowerlevel positions in the hierarchical divisions of labor of corporate units within domains or even excluding them altogether from entire institutional domains. The result is that classbased inequalities are supplemented by those based upon other kinds of categoric memberships, typically defined by nominal parameters.

At stake is the degree to which an institutional environment or set of institutional environments is stable. When parameters marking categoric unit membership are correlated or "consolidate” with each other, the salience of all increases, as does inequality in a society. When categoric unit membership is correlated with class and, in turn, with locations in divisions of labor of corporate unit, this consolidation only increases existing inequalities, thus generating tensions and conflict in a society while making the environments of corporate units increasingly unstable. In contrast, when parameters defining categoric unit membership “intersect” across all types of corporate units - communities, organizations, and groups — and at all places in the divisions of labor of these corporate units, people from different categoric units will have high rates of interaction, with the consequence that the salience of their categoric unit memberships will decline and status beliefs will lose much of their stigmatizing power. Under these conditions of intersection, integration increases because individuals are distributed across 
divisions of labor in corporate units of differentiated institutional domains, thereby reducing inequalities between members of categoric units and resource inequalities in a society; intersection of parameters makes the environments of organizations more diverse but much less volatile. Put another way, when this correlation breaks down and categoricunit membership is not consolidated with positions in the divisions of labor of corporate units, the tensions of stratification are less likely to pose threats to organizations because individuals are more likely to be recruited on the basis of more universalistic criteria (e.g., years of training, experience, etc.) rather than the particularism marking the consolidation parameters.

\section{Tying Together The Old and the New}

These mechanisms of structural interdependence can, we believe, inform the New Institutionalism, along a number of conceptual fronts. First, the Old Institutionalism conceptualizes some of the key dynamics that lead to divergence in organizational forms across time and space. New Institutionalism has primarily analyzed modern economic organizations influenced by the polity and legal sphere, and conversely, how the capitalist economy has had effects on polity and law (e.g., Thomas et al. 1987; Powell and DiMaggio 1991; Nee 2005). In the New Institutionalism, then, the cultural environment of any corporate unit is heavily slanted toward the meta-ideology combining the ideologies of capitalism, political democracy, positivistic law, science, and education (Abrutyn 2009). The types of organizations New Institutionalists typically analyze have existed for a few hundred years of human evolution; and, as is already evident, these societies are not necessarily stable. Convergence, then, is really a recent phenomenon driven by the greatly expanding scale of human social organization that has reached truly 
global proportions, with the organizational units in all of the institutional domains of hegemons becoming structural and cultural templates for other societies. The environments of organizational units in heretofore diverse societies thus begin to converge in the structural mechanisms integrating units and in the cultural meta-ideology governing the operation of these units. Coupled with the power of dominant nations to impose their organizational templates and cultures on dependent societies, there is a clear trend toward broad structural and cultural equivalences that can, to a degree, integrate the scale and reach of inter-institutional relations in inter-societal systems. Yet, to the degree that these structural and cultural isomorphisms are imposed on local structural and traditional cultural bases of integration, they generate the same long-term disintegrative potential evident when core corporate units in polity, economy, or religion impose structural templates and meta-ideologies on corporate units in diverse domains within a society.

To be sure, these linkages are vital to understanding how the Nation-State has become the legitimate political form in the 20th and 21st centuries, but it obfuscates the very real divergences across cases and the consequences of these divergences on people's lives, organizational forms, and societal interrelationships. However, examining the circulation of media of exchange provides a powerful tool to explain the divergence that occurs across cases about which Meyer and most New Institutionalists have little to say (Kraatz and Zajac 1996). For instance, Indonesia's statehood reflects the isomorphic forces of a Western meta-ideology without recognizing how the religious domain has affected the polity, law, and economy in ways that make Indonesia different from the U.S. or England. Likewise, to ignore the ways in which the religious and kinship domains 
influence local politics or economics in a small town in the Bible Belt of the U.S., while choosing to focus on how regulatory and/or normative isomorphism shapes organizational decisions, is to miss a force as powerful as political or legal isomorphism. Thus, the greater is the degree which different institutional domains exchange, the greater is the level of complexity and interdependency between institutional environments.

Furthermore it is clear the circulation of media of exchange and the metaideologies derived from the types of institutions which become dominant would be important to understanding how DiMaggio and Powell's organizational fields work. In an economic domain governed by capitalism, the ideology of wealth accumulation as a positive good that, in turn, makes polity, kinship, education, and science possible becomes a dominant tenant in the meta-ideology of the economy, with the ideologies built from love/loyalty, power, influence, learning, and knowledge having to accommodate this dominant tenant. In contrast, with a more authoritarian polity, all other ideologies must accommodate the ideology of power emphasizing that a strong state is a positive good used for the benefit of actors in all other domains. Or, if the ideology built from the medium of sacredness/piety from religion dominates the meta-ideology, then the ideologies built from other symbolic media must be accommodated to the belief that the word of supernatural forces and their human interpreters must be obeyed for the benefit of all in society. In essence, meta-ideologies simplify the cultural environment of any corporate unit engaged in inter-institutional exchanges, and to the extent that broad norms flow from these meta-ideologies, the simplified cultural environment generates some of the benefits of cultural equivalence that comes with segmentation while, at the same time, providing regulatory (and somewhat moralized) codes for regularizing far-reaching, often 
inter-institutional interdependencies. It is proposed that the greater is the degree of interdependency between institutional domains and the greater is the degree to which cooler media circulate across interdependent domains, the greater is the probability that structural isomorphic pressures and meta-ideologies will influence the operation of any given organizational unit.

Secondly, the Old Institutionalism throws into sharper relief than the New Institutionalism the problem of uncertainty and instability. Even the most repressive state, for example, cannot stamp out sacredness/piety in religion or love/loyalty in family (Froese 2009). They can, however, bend the ideologies of learning, science, law, and economy to the ideology of centralized and restrictive power, although even then the ideology of domination by power will eventually be challenged. Meta-ideologies simplify and often "corrupt" other ideologies built from the distinct generalized symbolic media of less dominant institutional domains, but these ideologies only mask over some of the inherent conflicts in the ideologies of different domains. When the dominant institutional domain imposes its ideology on actors in other domains, the cultural fissures that inevitably arise will eventually begin to disrupt the basis of integration. Yet, without the simplification and accommodation provided by meta-ideologies that integrate all institutional ideologies, symbolic media cannot circulate across corporate units in all institutional domains; and, moreover, the environments of any corporate unit in any domain become too complex, thus creating potential for structural disintegration. The greater the incompatibilities among the ideologies making up a meta-ideology and the more one ideology dominates without accommodating key tenets of other ideologies, the more unstable in the long run will be the structural and cultural environments of any 
organization and the more difficult will it become for any organization to navigate its immediate environment. For example, the more the state and the meta-ideologies built from the medium of power dominate rather than co-opt the ideologies of other domains, the more stable is the cultural and structural environments of non-state corporate units in the short-run, but the inherent tension among ideologies will eventually cause unstable environments in the longer run, thereby making adaptive responses by corporate units ever more difficult. Moreover, depending upon which ideology dominates the metaideology, the latter will generate outcomes that erode the capacity of institutional domains to respond to the selection pressures that originally led to their evolution. The result will be increased mal-adaptation and potential institutional collapse.

An industrial society dominated by state or religious ideologies will eventually grind down entrepreneurship and the dynamics of free markets to the point where there is insufficient productivity to meet (often rising) needs and expectations of individuals and corporate units. Or, on the other side, a wholly free market system without regulation by polity and law will, as the world has just seen, cause collapse of fiduciary markets, loss of liquidity, and decreased productivity so that the needs of actors dependent upon this productivity cannot be met, thus hastening not just economic disintegration but also the disintegration of all other domains in a society dependent upon economic outputs. Thus, the very integration of complexity can, over time, reduce the capacity of corporate units and the actors in these units to respond to the very selection pressures that caused their evolution.

A third contribution from the Old Institutionalism to the New Institutionalism is the delineation of varying bases of power and how these constrain organizational 
dynamics. The New Institutionalism has given an inordinate amount of attention to political and legal regulatory pressures as the loci for power and use its use to regulate other corporate units in other domains (cf. Edelman and Suchman 1997). Yet, at times, corporate units in other domains can also dominate and become regulatory forces in the environments of other corporate units. For example, an Islamic republic, relying upon Islamic Law, dominates in an entirely different way than the consolidation of the bases of power in a political democracy with a more autonomous legal system built from positivistic law (Ahkavi 1992). Given the variations in the configurations of bases of power, we propose that the greater is the degree to which domination relies on coercive mechanisms, the more unstable will the institutional environment become over the longrun and the more likely will isomorphic pressures and meta-ideologies come to constrain organizations. When domination is highly coercive, there is almost always a corresponding mobilization of the symbolic base of power around the ideology of the polity and the administrative apparatus for monitoring and enforcing conformity to directives from political leaders. Material incentives, under these conditions, are used much less. Thus, this pattern of domination can integrate corporate actors in diverse domains in the short term, but over time, the combination of coercive use of physical force, the imposition of meta-ideologies dominated by the ideology of the repressive state, and the use of administrative structures to monitor and sanction individual and corporate actors erodes the legitimacy of this pattern of consolidated power. Essentially, when the environments of organizations become dominated by physical, administrative, and symbolic constraints, corporate units in all institutional domains begin to withdraw legitimacy rather than simply adapt to a repressive environment. New Institutionalism 
ignores such systems, which unnecessarily constrain their models and theoretical principles (e.g., Scott 2001). Hence, the greater is the degree to which domination relies on material incentives and uses coercion in strategic ways, the more stable will be institutional environment and the less likely are isomorphic pressures and metaideologies to constrain organizations.

Where domination reserves coercion as a last resort and, instead, relies on the commitments of actors to ideologies and meta-ideologies, the use of administrative structures in a more facilitative than coercive way, the heavy reliance on material incentives (e.g., subsidies, tax credits, and tax rates), and the formation of metaideologies emphasizing free markets, limited activities of a democratic polity, and positive law, domination is less constraining but, in the long run, more effective in integrating corporate units in societies revealing high levels of institutional differentiation. In this configuration the environments of corporate units are less constraining, allowing organizations to adapt to a mix of integrative mechanisms, including the ideologies of a particular domain, the meta-ideology of dominant domains, the material incentive provided by polity, the legal codes and its adjudicative structures (i.e., courts), the reliance on coercive power when legal codes are violated, and the use of administrative structures for achieving corporate-unit goals. This kind of environment is more complex and uncertain, but it is less restrictive and enables organizations more options in realizing their goals, in forming exchange relations with other corporate units within and between domains, and in adapting to a more complex environment composed of (1) other corporate units in diverse domains, (2) generalized symbolic media circulating across domains, (3) meta-ideologies legitimating corporate units actions as 
well as the unequal distribution of resources within stratification system, (4) status beliefs about members of differentially valued categoric units, (5) availability of various material incentives from polity, and (6) legally regulated strategic use of coercive and administrative bases of power. The result is reduced tensions among corporate units and centers of domination

In addition, patterns of intersecting parameters have large effects on institutional stability. The more the environments of corporate units are free of the tensions and conflicts over inequalities consolidated with categoric unit memberships, the more organizations can focus on the meta-ideologies legitimating diverse institutional domains than those meta-ideologies legitimating the stratification system. In turn, the more organizations will operate in more stable environments where generalized symbolic media of exchange, institutional ideologies, and normative systems derived from these ideologies regularize corporate unit-actions. And the more stable immediate environments, the more pronounced are the integrative effects of other mechanisms of structural interdependencies—exchange, embedding/inclusion, mobility, and overlap. Furthermore, if enough corporate units in all institutional domains are able to stabilize their local environments through facilitating intersection of parameters within the divisions of labor, the general environment of all domains becomes more stable and less prone to conflicts arising from inequalities in the stratification system.

Fourth, organizational fields as conceptualized by DiMaggio and Powell seem to over-emphasize horizontal relationships between organizations. Institutional environments are not restricted to these horizontal relationships because power is almost always being imposed from without (either in the case of the polity and/or law providing 
regulatory pressure, or some other institutional domain such as the economy or religion). Organizational nesting occurs in which multiple corporate units are arranged into a surpaorganizational "fields," which seeks to coordinate and control the behavior of the congeries of organizations from within the institutional domain itself. The effects of embedding and inclusion on organizational dynamics, however, depends greatly upon the types of power used by corporate units with authority and on the types of media circulating across boundaries. Take, for instance, two professional associations and the variation in isomorphic pressure, conformity across organizational units, and adaptive strategies employed in both cases. The American Sociological Association's authority rests on symbolic power revolving around ideological commitments (and perhaps vague material incentives) to the association's ethics, norms, and definition of reality. The result of this weak base of symbolic power is highly diverse sociology departments across the nation, wide variations in what is considered sociological, and large differences in how sociologists are trained. In contrast, the American Bar Association has consolidated both symbolic power alongside some degree of coercive power (as franchised by the polity) that can be converted into incentive-based power (such that it can decertify an individual or an entire corporate unit—i.e., a law school). The result is a higher degree of isomorphic pressure, conformity among social units, and shared meta-ideology across institutional boundaries because conformity tends to produce regularized exchanges with extra-legal corporate units.

Fifth, similar to the effects of nesting, high rates of mobility facilitate regularized exchanges between corporate units across institutional domains. The basic generalization to be derived from these conclusions is that the more differentiated are corporate units 
within and between institutional domains, the more uncertain is the environment of any given corporate unit. Under this condition, there is strong pressure to regularize mobility within and across domains. Corporate units do so by relying on labor markets and, within these markets, the imposition of credential requirements on those whom they employ or allow to become incumbent in a corporate unit. The more these credential requirements facilitate the movement of individuals from diverse categoric units into a wide range of locations in the divisions of labor of corporate units and the more these individuals carry with them the symbolic media and ideologies of another domain, even as they carry distinctive cultures of their categoric units, the more stable and regularized the environments of the corporate units involved will become, and the greater will be the degree of structural and cultural integration among corporate units within and between institutional domains.

\section{FINAL THOUGHTS}

The environments in which organizations find themselves are much more complex and dynamic than the conceptualizations suggested by the New Institutionalists. Institutions are not simply cultural patterns which endure, but more importantly are structural and cultural elements with consequences for organizations vital to understanding human societies and organizational dynamics. Durkheim (1895:see preface to the second edition) once argued that a science of society was synonymous to the study of institutions, not organizations. New Institutionalists have successfully downsized Durkheim's assertion by providing insights into the dynamics of the meso-level but, in so doing, have unwittingly pushed the study of institutions and, indeed, macro-level dynamics in general into the periphery. This paper has sought to bring Old 
Institutionalism back to the center of sociological analysis in general and organizational analysis in particular, with the hopes of suggesting relationships between the institutional and organizational levels of analysis that might prove useful to the New Institutionalism. The process of autonomy, the circulation of generalized media of exchange, the effects of stratification, and the varying modes of integration within a given institutional domain all have very important effects on organizations. These insights have been largely ignored by contemporary sociologists for many reasons, but when removed from their old functionalist roots, the Old Institutionalism can offer powerful explanatory tools for the New Institutionalism, if it wants to be more than a time-bound theory seeking to explain phenomena during a small slice of human evolutionary history.

\section{REFERENCES}

Abrutyn, Seth. 2009. "Towards a General Theory of Institutional Autonomy." Sociological Theory 27:449-65.

Abrutyn, Seth and Kirk Lawrence. 2010. "From Chiefdoms to States: Toward an Integrative Theory of the Evolution of Polity." Sociological Perspectives 53:41949

Adams, Robert McC. 1966. The Evolution of Urban Society: Early Mesopotamia and PreHispanic Mexico. Chicago: Aldine Publishing Company.

Akhavi, Shahrough. 1992. "The Clergy's Concepts of Rule in Egypt and Iran." Annals of 
the American Academy of Political and Social Science 524:92-102.

Berger, Joseph, Bernard P. Cohen, and Morris Zelditch Jr. 1972. "Status Characteristics and Social Interaction." American Sociological Review 37:241-255.

Biggart, Nicole Woolsey. 1991. "Explaining Asian Economic Organization: Toward a Weberian Institutional Perspective." Theory and Society 20:199-232.

Blau, Peter M. 1977. "A Macrosociological Theory of Social Structure." American Journal of Sociology 83:26-54. 1994. Structural Context of Opportunities. Chicago: University of Chicago Press.

Blau, Peter M., Terry C. Blum, and Joseph E. Schwartz. 1982. "Heterogeneity and Marriage." American Sociological Review 47:45-62.

Bourdieu, Pierre. 1984. Distinction: A Social Critique of the Judgment of Taste. Translated by R. Nice. Cambridge: Harvard University Press.

DiMaggio, Paul and Walter W. Powell. 1983. "The Iron Cage Revisited: Institutional Isomorphism and Collective Rationality in Organizational Fields." American Sociological Review 48:147-160.

Dobbin, Frank and John R. Sutton. 1998. "The Strength of a Weak State: The Rights Revolution and the Rise of Human Resources Management Divisions." American Journal of Sociology 104:441-476.

Durkheim, Emile. 1895. The Rules of Sociological Method and Selected Texts on Sociology and its Method. Translated by W. D. Halls. New York: Free Press.

Earle, Timothy. 1991. Chiefdoms: Power, Economy, and Ideology. Cambridge: Cambridge University Press. 2002. Bronze Age Economics: The Beginnings of Political Economies. Oxford: Westview Press. 
Edelman, Lauren B. and Mark C. Suchman. 1997. "The Legal Environments of Organizations." Annual Review of Sociology 23:479-515.

Eisenstadt, S.N. 1963. The Political System of Empires: The Rise and Fall of the Historical Bureaucratic Societies. New York: Free Press.

Fligstein, Neil. 1996. "Markets As Politics: A Political-Cultural Approach to Market Institutions." American Sociological Review 61:656-673.

Froese, Paul. 2009. The Plot to Kill God: Findings from the Soviet Experiment in Secularization. Berkeley: University of California Press.

Habermas, Jürgen. 1985. The Theory of Communicative Action, 2 vols. Boston: Beacon Press.

Hannan, Michael T. 1988. "Organizational Population Dynamics and Social Change." European Sociological Review 4:95-109.

Hannan, Michael T. and John Freeman. 1977. "The Population Ecology of Organizations." American Journal of Sociology 82:929-964.

Hawley, Amos H. 1986. Human Ecology: A Theoretical Essay. Chicago: University of Chicago Press.

Hirsch, Paul M. 1975. "Organizational Effectiveness and the Institutional Environment." Administrative Science Quarterly 20:327-244.

Jepperson, Ronald L. 1991. "Institutions, Institutional Effects, and Institutionalism." Pp. 143-63 in The New Institutionalism of Organizational Analysis, edited by W. W. Powell and P. J. DiMaggio. Chicago: The University of Chicago Press.

Johnson, Allen W. and Timothy Earle. 2000. The Evolution of Human Societies: From Foraging Groups to Agrarian State. Stanford: Stanford University Press.

Kraatz, Matthew S. and Edward J. Zajac. 1996. "Exploring the Limits of the New Institutionalism: The Causes and Consequences of Illegitimate Organizational Change." 
American Sociological Review 61:812-836.

Lenski, Gerhard. 1966. Power and Privilege: A Theory of Social Stratification. New York: McGraw-Hill.

Luhmann, Niklas. 1984. Social Systems. Translated by J. Bednarz Jr. and D. Baecker. Stanford: Stanford University Press.

Mann, Michael. 1986. The Sources of Social Power: A History of Power From the Beginning to A.D. 1760, vol. 1. Cambridge: Cambridge University Press.

Maryanski, Alexandra and Jonathan H. Turner. 1992. The Social Cage: Human Nature and the Evolution of Society. Stanford: Stanford University Press.

Meyer, John W. 1977. "The Effects of Education as an Institution." American Journal of Sociology 83:55-77. . 1987. "The World Polity and the Authority of the Nation-State." Pp. 4170 in Institutional Structure: Constituting State, Society and the Individual, edited by G. M. Thomas, J. W. Meyer, F. Ramirez, and J. Boli. Newbury Park, CA: Sage.

Meyer, John W. and Brian Rowan. 1977. "Institutionalized Organizations: Formal Structure as Myth and Ceremony." American Journal of Sociology 83:340-363.

Meyer, John W., Francisco O. Ramirez, and Yasemin Nuhoglu Soysal. 1992. "World Expansion of Mass Education, 1870-1980." Sociology of Education 65:128-149.

Meyer, John W., Joane Nagel, and Conrad W. Snyder Jr. 1993. "The Expansion of Mass Education in Botswana: Local and World Society Perspectives." Comparative Education Review 37:454-475.

Nee, Victor. 2005. "The New Institutionalisms in Economics and Sociology." Pp. 49-74 in The Handbook of Economic Sociology, edited by N. J. Smelser and R. Swedberg. Princeton: Princeton University Press.

Nissen, Hans J. 1988. The Early History of the Ancient Near East, 9000-2000 B.C. 
Translated by E. Lutzeier. Chicago: University of Chicago Press.

North, Douglass C. 2005. "Capitalism and Economic Growth." Pp. 41-52 in The Economic Sociology of Capitalism, edited by V. Nee and R. Swedberg. Princeton: Princeton University Press.

Ouchi, William G. 1980. "Markets, Bureaucracies, and Clans." Administrative Science Quarterly 25:129-141.

Parsons, Talcott and Neil J. Smelser. 1956. Economy and Society: A Study in the Integration of Economic and Social Theory. New York: The Free Press.

Postgate, J.N. 1977. The First Empires. Oxford: Elsevier-Phaidon.

Powell, Walter W. and Paul J. DiMaggio. 1991. The New Institutionalism in Organizational Analysis. Chicago: The University of Chicago Press.

Powell, Walter W. 1999. "Neither Market Nor Hierarchy: Network Forms of Organizations." Research in Organizational Behavior 12:295-336.

Ridgeway, Cecilia L. 2001. "Inequality, Status, and the Construction of Status Beliefs."in The Handbook of Sociological Theory, edited by J. H. Turner. New York: Kluwer/Plenum. . 2006. "Status Construction Theory." Pp. 301-23 in Contemporary Social Psychological Theories, edited by P. J. Burke. Stanford: Stanford University Press.

Sailer, Lee D. 1978. “Structural Equivalence.” Social Networks 11:73-90.

Scott, W. Richard. 2001. Institutions and Organizations. Thousand Oaks, CA: Sage. Selznick, Philip. 1948. "Foundations of the Theory of Organizations." American Sociological Review 13:25-35.

Simmel, Georg. 1907. The Philosophy of Money. Boston: Routledge \& Kegan Paul. 
Sutton, John R. and Frank Dobbin. 1996. "The Two Faces of Governance: Responses to Legal Uncertainty in U.S. Firms, 1955 to 1985." American Sociological Review 61:794811.

Sutton, John R., Frank Dobbin, John W. Meyer, and W. Richard Scott. 1994. "The Legalization of the Workplace." American Journal of Sociology 99:944-971.

Thomas, George M., John W. Meyer, Francisco O. Ramirez, and John Boli. 1987. Institutional Structure: Constituting State, Society, and the Individual. Newbury Park, CA: Sage.

Turner, Jonathan H. 1995. Macrodynamics: Toward a Theory on the Organization of Human Populations. New Brunswick: Rutgers University Press. . 2010. Theoretical Principles of Sociology, volume 1 on Macrodynamics. New York: Springer.

Turner, Jonathan H. and Alexandra Maryanski. 2008. On The Origin of Societies by Natural Selection. Boulder, CO: Paradigm Press.

Weber, Max. 1958. The City. Translated by D. Martindale and G. Neuwirth. New York: Collier Books. 1967. Max Weber on Law in Economy and Society, Edited by M. Rheinstein.

Translated by E. Shils and M. Rheinstein. New York: Simon and Schuster. . 1978. Economy and Society: An Outline of Interpretive Sociology, vol. 1-2,

Edited by G. Roth and C. Wittich. Berkeley: University of California Press. Yoffee, Norman. 2005. Myths of the Archaic State: Evolution of the Earliest Cities, States, and Civilizations. Cambridge: Cambridge University Press. 